\title{
Analysis and Prediction of Long-term Settlement of Metro Shield Tunnel in Saturated Sand
}

Jianzheng Liu ( $\sim$ liujianz1976@163.com )

China Railway First Survey and Design Institute Group Co Ltd

Yang Yixin

Zhengzhou University

Yang Chunjie

Zhengzhou University

\section{Research Article}

Keywords: saturated sand, shield tunnel, long-term settlement, monitoring data, settlement prediction

Posted Date: March 23rd, 2021

DOI: https://doi.org/10.21203/rs.3.rs-315813/v1

License: (c) (1) This work is licensed under a Creative Commons Attribution 4.0 International License. Read Full License 


\section{Abstract}

based on the existing monitoring data, this paper uses the matured data method to analyze and predict the long-term settlement of the subway shield tunnel, and comprehensively analyzes the long-term settlement of the subway shield tunnel in the saturated sand layer of Zhengzhou. Logical curve model is used. Etc. separately predict the long-term settlement of the Zhengzhou metro shield tunnel, and combine the prediction results to summarize the characteristics of the prediction model to obtain a prediction model suitable for the long-term settlement of the subway shield tunnel in the sandy soil area represented by Zhengzhou, which can be used for the operation of the Zhengzhou subway tunnel. Management and similar engineering projects provide a certain reference basis.

\section{Introduction}

With the continuous promotion of urbanization in China, many problems in environment and transportation have been exposed, which seriously affect the development of cities and people's pursuit of a better life. Subway can make full use of space and avoid ground traffic jam. Therefore it is favored by major cities for its large traffic volume, fast speed and punctuality. The construction of subway has become a sign whether the economy is developed or not. With the boom of subway construction, more and more subway shield tunnels have been put into operation. For instance, Beijing subway, the earliest one in China, has been put into operation for more than 40 years. With the increase of operation period of built subway, the long-term action of cyclic load of trains will cause settlement deformation of foundation soil in shield tunnel. Settlement or differential settlement of foundation soil of tunnel will seriously affect driving safety and increase costs in operation and maintenance. Long-term settlement of shield tunnels in the subway has been paid more and more attention by researchers. The operation time of the subway in sandy soil layer is short, and there is no research on actual measurement and analysis of settlement law in operation period. Therefore, it is necessary to study the long-term settlement of shield tunnel in saturated sand.

At present, there are two types of research methods for calculation and prediction of foundation settlement. The first type is based on geomechanical theory, combined with constitutive or empirical models of various soils, finite element numerical calculation or layered summation calculation of settlement. The second type is forecasting method by calculating the relationship between settlement and time based on measured data. Cheng. (2014), Liu. (2014), and Zhang et al. (2011) had studied the deformation rules of deep foundation pit at subway station in tunneling with the method of FLAC3D numerical simulation. Amir et al. (2017) had studied the model uncertainty of settlement estimation models through a systematic comparison between model predictions and past performance data derived from instrumentation.

The second method (Liu et al. 2014) is to obtain the development trend of settlement and deformation based on the existing measured data, and to use appropriate mathematical model to predict the development of settlement after that. Tan et al. (2016) studied the settlement of a subway tunnel from 
the theoretical and numerical analyses based on the monitoring data. Ahangari et al. (2015) had applied modern intelligent methods to predict subway settlement.

Although the experience curve model cannot reveal the internal mechanism of deformation at the micro level, which was summarized by the results of settlement and deformation monitoring during a large number of engineering constructions and operation periods in the past, combined with actual-time series data, without considering the microscopic stress-strain relationship, it can be directly viewed from the macro level. For example the prediction of settlement deformation is convenient and reliable, and easy for process control. A more realistic prediction effect can be achieved combined with the analysis of the construction process, the influence of the surrounding environment, and the principles of physical mechanics.

From the point of view of constitutive relation and one-dimensional consolidation theory, Zai et al. (2000) proved that the settlement-time curve of foundation is " $S$ " type in mathematics and mechanics, and divided it into occurrence stage, development stage, maturity stage and reaching limit stage in mechanism. Many scholars have put forward settlement prediction models of many logic functions based on the general law of things development (Wu et al. 2001, Fan et al. 2007, and Zhang et al. 2017).

Logistic settlement prediction model, also known as inference curve model and growth curve model, was originally proposed by Zai et al and Mei et al (2000). It is a widely used prediction method for foundation settlement of silt and sand layer developed in recent years because of its good astringency.

The ground subsidence, crown settlement and convergence displacement caused by the cut tunnel are monitored during the tunneling construction and the results of monitoring data for them are analyzed by Bai et al (2013). According to the tracing monitoring results of surface settlement and deformation of method of PBA in large-span tunnel used in the construction of the of Shenyang subway station, Song et al. (2012) had analyzed the ground surface settlement characteristics and laws influenced by the process of tunnel excavation influence.

Based on the existing monitoring data, this paper uses the measured data method to analyze and predict the long-term settlement of the subway shield tunnel, comprehensively analyzes the long-term settlement of the subway shield tunnel in the sand layer of Zhengzhou area, and uses the logic curve model to analyze the long-term settlement of the Zhengzhou subway shield tunnel. Combined with the prediction results, the prediction summarize the characteristics of the prediction model, and obtain a suitable prediction model for the long-term settlement of the subway shield tunnel in the sandy soil area represented by Zhengzhou. And it can provide a certain reference for the operation and management of the Zhengzhou subway tunnel and similar projects.

\section{Project Summery}

Zhengzhou Metro Line 1 started to construct on June 6, 2009. The Phase I line opened for trial operation on December 28, 2013 and Phase II project was on January 12, 2017. Zhengzhou Metro Line 1 starts at 
Henan University of Technology Station and ends at The New Campus of Henan University Station with a total length of $41.2 \mathrm{~km}$. All of them are underground lines with a total of 30 stations, which are all underground stations.

\section{1 Geological conditions}

\section{(1) Engineering geology}

The engineering geological conditions are similar along the eastern section of Zhengzhou Metro Line 1, and the soil layer is relatively continuous and stable: there are 5 interval projects between South Yellow River Road Station and City Sports Center Station. The strata uncovered within 45. 0m exploration depth along the line are divided into Holocene (Q4) and Quaternary Upper Pleistocene (Q3) strata. According to geological report and design documents of Engineering investigation, the underlying foundation soil layer of shield tunnel is mainly silty sand layer, and the line strata of this section are mainly miscellaneous fill, silt, fine sand and silty clay.

(2) Hydrogeological conditions

The groundwater aquifer is divided into two layers. The upper layer of phreatic water mainly occurs in silt and silty clay above $10.0 \nabla 14.0 \mathrm{~m}$. It is an impermeable aquifer and is mainly affected by the replenishment of atmospheric precipitation and groundwater exploitation; confined water is mainly Occurs in the sand layer below 8.0 to $12.0 \mathrm{~m}$, it is a strong water-permeable layer and has a slight pressure-bearing property.

\section{2 Monitoring summery}

This monitoring project starts settlement monitoring after the completion of the track laying project. The content of settlement monitoring includes: the settlement of the main structure of the underground station, the settlement of the track bed of the track line, the differential settlement of the connection between the station and the section and the communication channel as well. The settlement monitoring during the operation period has lasted for 12 periods since November 2014.

According to the actual situation of the subway, the reference points are buried in the stable track bed in the subway station, and one point per 30 meters is arranged in each station. Each station selects 6 reference points, averagely divided into both side of the line. Settlement monitoring points are arranged at intervals of 30 meters along the tunnel line. What's more, the key monitoring objects, special sections and deformation joints are densely arranged according to the actual situation. They are arranged in the middle of the section of the track bed structure. While at corners, they are appropriately arranged on the center line or outside to ensure a proper line of sight length according to the site conditions. The specific layout of monitoring points is shown in Fig. 1.

\section{Monitoring Results And Analysis}


There are 21 sections (including access lines) in Phase I of Zhengzhou Metro Line 1. The buried depths of strata and tunnels under each section are different. The water table also differs and varies with time; ground structures (structures), and traffic facilities and additional loads all differ in varying degrees. The strata crossing conditions change stably and continuously and the influence of ground facilities is affected. Small representative intervals can be analyzed independently, which is more conducive to summarizing laws for settlement prediction. According to the monitoring data of subway tunnel settlement drawing 'cumulative settlement curve at monitoring point' and 'cumulative settlement-time curve at monitoring point' can intuitively understand the process and trend of tunnel settlement ${ }^{[2]}$, which is the basis of settlement prediction.

\section{(1) Boxue Road - City Sports Center}

The development results of cumulative settlement at each stage of settlement measuring points on left and right lines of Bo-volume interval are shown in Fig. 2. It can be seen from the figure that different degrees of settlement have occurred in the interval tunnel, two settlement troughs have been generated in the right tunnel and the left as well. The curve distribution of the left line is sparse from Phase 5 (April 12, 2016) to Phase 6 (August 21, 2016) and the right line is sparse from Phase $5($ April 13, 2016) to Phase 6 (July 31, 2016). Greater settlement occurs between the two phases with an average settlement of about $10 \mathrm{~mm}$ and the settlement rate is the highest during the monitoring period. It can be seen from the density of the distribution of settlement curves in each period that most of the curves in the last two periods almost coincide with each other and that settlement development enters a stable state.

The frequency distribution of settlement on the left and right lines of the Bo-Ti interval is shown in Fig. 3. There are 73 measuring points on the left line among them. The final monitoring results show that the cumulative settlement is up to $62.81 \mathrm{~mm}$ and the average settlement is $42 \mathrm{~mm}$. The measure point of the settlement value above $35 \mathrm{~mm}$ is more than $85 \%$. The settlement value between $35 \mathrm{~mm} \sim 55 \mathrm{~mm}$ accounts for about $81 \%$, and the total number of measurement points on the right line is 71 , The final monitoring result shows that the cumulative settlement is $73.15 \mathrm{~mm}$, and the number of measurement points with a settlement exceeding $35 \mathrm{~mm}$ accounts for more than $90 \%$ of the total The point settlement value is between $35 \mathrm{~mm}$ and $55 \mathrm{~mm}$, accounting for $70.4 \%$.

The representative measurement point settlement development curves of the left and right lines of the interval are shown in Fig. 4:

It can be seen from the figure: (1) From the 5th to the 6th Phase, a large settlement occurred between them, and the settlement rate is the largest during the monitoring period; (2) The settlement development curve can be roughly divided into four Stage: In the first stage, the subsidence developed slowly in the initial stage of operation, and the curve in the above figure shows a slight increase in the first two phases. In the second stage, the settlement rate continues to increase from the third to the sixth phase of postconstruction monitoring. The sedimentation rate reaches the maximum in the 6 th stage. The third stage is from the 6 th to the 10 th stage, and the settlement continues to develop at a certain rate, which is 
shown as an approximate straight line in the figure. The fourth stage is the attenuation and stable period from the 10th to the 12th stage, and the settlement rate decays to a small amount. At the same time, the settlement hardly develops further, and goes to convergence. The overall curve is in an "S" shape. From Figure 4 combined with Figure 2, it can be seen that some of the measurement points have rebound deformation(above range of 0-8 $\mathrm{mm}$ ) during the first and second monitoring periods. It might that the water table drops during the construction as precipitation and gradually rise at the operation period. The rebound relieved the effective stress in the soil layer, resulting in the uplift of the soil layer and the tunnel as a whole.

(2) Huanghe South Road - Nongye South Road

The development results of the cumulative settlement of the left line and the right line settlement measuring points between the Yellow River and the agricultural area are shown in Fig. 5. It can be seen from the figure that the settlement along the mileage of the left and right tunnels is basically unchanged, the curve is stable, and there is no seriously undulant. The last two monitoring curves almost coincide with each other, showing a stable trend, and some sections show a slight rebound (more intuitive in Fig. $6)$.

In Fig. $6 \mathrm{a}$ and Fig. 6b, the settlement time development curves of the two representative measuring points in the East and West sections of the left line are respectively shown. From the figure, it can be seen that: (1) from the 5th to the 6th phase of the western section. The settlement occurred between the two phases, and the rate was the largest in the monitoring period. (2) From Fig. 6, it is obvious that the development process of the settlement is: At the beginning, the settlement speed is small, but the speed is increasing to a certain extent (phase 5 to phase 6 in the figure), then gradually attenuated process starts until it enters into a stable state. In Fig. $6 \mathrm{a}$ and Fig. 6b, there are slight fluctuations and rebound phenomena in the settlement curve monitoring period, but it still has the characteristics of ' $S$ ' on the whole.

The frequency distribution of the left and right lines in the Huang to Nong interval are as 4. 11a and 4. 11b. There are 35 measuring points on the left line and the right line as well. The cumulative settlement distribution is relatively concentrated. The final phase monitoring results show that the cumulative settlement of the left line is $21 \mathrm{~mm} \sim 28 \mathrm{~mm}$, and the settlement of the right line is $25 \mathrm{~mm} \sim 34 \mathrm{~mm}$.

\section{Long-term Settlement Prediction}

\section{1 Logic model establishment}

The logic curve is used to fit and analyze the measured settlement data of each measuring point, and two target curves are selected for fitting respectively. The expressions are: 


$$
\begin{aligned}
& S_{t}=\frac{A_{1}-A_{2}}{1+\left(t / t_{0}\right)^{p}}+A_{2} \\
& S_{t}=\frac{k}{1+a e^{-b t}}
\end{aligned}
$$

Before the fitting analysis, the measured data were processed. The post construction monitoring time was selected as the starting point of time, and the time was in the unit of month (30. 4 days per month on average). In the foregoing settlement time curve analysis, it can be seen that in the initial stage of monitoring, the cumulative settlement decreases (rebound in the short term). In order to better predict the settlement, the abandonment or not is selected as the comparative analysis to observe the fitting sensitivity of the logical model to the unreasonable points in the early stage.

The following analysis is carried out for the R $16 \mathrm{C} 12$ monitoring point in the Huang-Nong interval. The monitoring settlement-time curve is shown in Fig. 8a, and the curve fitting of the two logic models is shown in Fig. 8b, the results of the fitting parameters are shown in Table 1.

Table 1 R16C12 monitoring point logistic model fitting parameters

\begin{tabular}{ccc}
\hline Model & Logic curve one & Logic curve two \\
\hline Equation & $y=A_{2}+\left(A_{1}-A_{2}\right) /\left(1+\left(x / x_{0}\right)^{\wedge} p\right)$ & $y=\mathrm{a} /\left(1+b^{*} \exp \left(-k^{*} x\right)\right)$ \\
$A_{1}$ \a】 & -1.122 & 30.365 \\
$A_{2}(\mathrm{~b})$ & -32.118 & 64.447 \\
$\mathrm{x}_{0}(\mathrm{k})$ & 27.535 & 0.156 \\
$\mathrm{p}$ & 4.031 & \\
Reduced Chi-Sqr & 1.812 & 2.288 \\
$R^{2}(\mathrm{COD})$ & 0.991 & 0.987 \\
$R^{2}$ after adjustment & 0.987 & 0.984 \\
\hline
\end{tabular}

According to fitting results, the fitting effect of the above two logical models is very proper, $R^{2}$ is greater than 0.98 . On the whole, the fitting results of the two models have little difference, and the prediction of the later stage of the logic curve 2 is slightly larger than that of the logic curve 1.

After discarding the first 3 measured data points, the remaining measured data was fitted, and the fitting effect was added and analyzed after deducting the 4th (5) data point. The fitting results are shown in Figure 4. 14, and the fitting parameters of the logistic model with different numbers of monitoring data are shown in Table 2. It can be seen from the fitting results that the $R^{2}$ of the two models are both greater than 0.96 . Whether some data points are discarded in the early stage has little influence on the fitting effect, and the influence on the later prediction is basically negligible, indicating that the fitting prediction effect of settlement in logic curve is not sensitive to several unreasonable data points.

Table 2 Fitting parameters of the logistic model with different numbers of monitoring data 


\begin{tabular}{|c|c|c|c|c|c|}
\hline Serial number of data point & $4-13$ & $5-13$ & $4-13$ & $5-13$ & $6-13$ \\
\hline Logic model & \multirow{2}{*}{\multicolumn{2}{|c|}{$\begin{array}{l}\text { Logic curve one } \\
2+\left(A_{1}-A_{2}\right) /\left(1+\left(\mathrm{x} / \mathrm{x}_{0}\right)^{\wedge} \mathrm{p}\right)\end{array}$}} & \multicolumn{3}{|c|}{ Logic curve two } \\
\hline Equation & & & $\mathrm{y}=$ & $/\left(1+b^{*}\right.$ & $\left.x p\left(-k^{*} x\right)\right)$ \\
\hline$A_{1} \mathrm{\square a} \square$ & 0.665 & 6.940 & 30.34 & 30.59 & 30.98 \\
\hline$A_{2}^{\square \mathrm{b} \square}$ & -33.02 & -34.45 & 65. 41 & 51.90 & 36.58 \\
\hline $\mathrm{x}_{0} \square \mathrm{k} \square$ & 27.04 & 24.69 & 0.157 & 0.148 & 0.135 \\
\hline $\mathrm{p}$ & 3. 53 & 2.83 & & & \\
\hline Reduced Chi-Sqr & 2.46 & 2. 79 & 2.98 & 3.26 & 3. 65 \\
\hline$R^{2}(\mathrm{COD})$ & 0.985 & 0.980 & 0.979 & 0.972 & 0.958 \\
\hline$R^{2}$ after adjusting & 0.978 & 0.968 & 0.973 & 0.962 & 0.941 \\
\hline
\end{tabular}

Logic model conforms to the development law of long-term settlement of subway in sandy soil layer, and the fitting prediction effect of settlement is not sensitive to individual unreasonable data points. The abandonment of some data points in early stage has little influence on fitting effect, and the data is easy to process, which is suitable for long-term settlement prediction of the whole operation period.

\section{Conclusion}

Based on the existing monitoring data, this paper uses the measured data method to analyze the longterm settlement of the subway shield tunnel, and comprehensively analyzes the long-term settlement of the subway shield tunnel in the saturated sand layer in Zhengzhou area. The gray model, hyperbolic model, logical curve model, etc, are respectively used to predict the long-term settlements of the shield tunnels of Zhengzhou Metro, and the following conclusions are drawn:

1. The settlement level of each section is different. The settlement level of the western section is small, generally $10 \sim 20 \mathrm{~mm}$, and the settlement is relatively stable along the tunnel. However the settlement of the eastern section is relatively large, most of which are above $30 \mathrm{~mm}$, and there are subsidence depressions. Reason analysis: There are a large number of building facilities on the ground along the western section of the line, which causes additional stress on the layer where the tunnel is located, consolidate and compact the soil layer. What's more, the existence of additional stress is equivalent to an increase in the depth of burial, making the location layer have a higher enclosure. The ground along the eastern section is mostly located in spacious areas, and there are no dense built ground buildings (for example, the ground along the Dong-Bo interval is an orchard), and the surrounding rock pressure level is relatively low. The conclusion drawn from the previous test chapter is that the surrounding rock pressure is higher, and the cyclic cumulative deformation produced is smaller. In addition, some areas are in the development period, and there may be foundation pit precipitation, which is affected by pumping or precipitation. The decrease of the water table will increase the effective stress, resulting in consolidation settlement, and at the same time, the effective stress will increase the penetration force during the porous flow process.

2. The settlement-time curve was drawn for multiple representative measuring points in each interval, and it was found that there is a general "S"-shaped development law. It can be roughly divided into four stages: slow development period, accelerated development period, declining development period, and stable period. Reason analysis: The in-situ soil deposited after geological age has a 
certain stress history, strong structure, and the initial loading settlement deformation speed is very small; as the number of cyclic loading increases, the soil absorbs vibration energy and occurs between soil particles The deformation rate increases; after the particles are rearranged, the soil is denser. As the loading continues, the resistance to movement between the soil particles becomes larger and the settlement rate becomes smaller and smaller. The soil becomes dense under the action, and the soil particles cannot continue to overcome the resistance so as to rearrange under the current load. Then the pores no longer decrease, and the settlement basically doesn't develops any longer. On the other hand, the groundwater level affected by the construction period gradually rises in the early stage of operation, and the soil rebounds to offset part of the settlement caused by subway operation in the early stage of operation.

3. In the interval cumulative settlement curve chart and the settlement-time curve of the measuring point, it can be seen that some lines rebound during the development process of settlement, and the rebound phenomenon is often more obvious at the beginning and end of settlement. obvious. Reason analysis: The deformation rate in the early and late stages of settlement is small, and the influence of the rise and fall of underground water level on settlement is not easily covered by the overall settlement trend, while the medium-term settlement rate is large, and the fluctuations in settlement caused by underground water level fluctuations are likely to be covered It can't be shown, not obvious.

4. The long-term settlement of the shield tunnel of Zhengzhou Metro was predicted, combined with the characteristics of the prediction result analysis model, a prediction model suitable for the long-term settlement of the subway shield tunnel in the sandy soil area represented by Zhengzhou was obtained: the logical model conforms to the sandy soil layer subway Long-term settlement "S" development law, settlement prediction effect is not sensitive to individual unreasonable data points, discarding some of the data points in the early stage has little impact on the fit effect, and the impact on the later prediction is basically negligible, and the data is easy to process and the prediction model is suitable for long-term settlement prediction during the entire operation period.

\section{Declarations}

\section{Author contribution statement}

Jianzheng Liu: Investigation - editing and supervision. Chunjie Yang: Writing, editing - data analysis and original drafts. Yixin Yang: Writing - editing and checking.

\section{Data availability statement}

The data supporting the results of this study can be obtained from the corresponding author upon reasonable request.

\section{Conflict of interest statement}

The authors do not have any possible conflicts of interest. 


\section{References}

Cheng YL (2009) Analysis of Deep Foundation Pit of Subway Station[J]. Advanced Materials Research, 2014, 3381: 1570-1574.

Liu YL (2014) Numerical Analysis of the Deformation Law of Deep Foundation Pit of Subway Station by FLAC3D[J]. Advanced Materials Research, 2014, 3140(1831): 62-67.

Zhang HZ, Feng YF et al (2011) Study on the Deformation Characteristics of Supporting System of Deep Foundation Pit in Subway Station Construction[J]. Advanced Materials Research, 2011, 1269(492): 546551.

Khademian Amir, Faramarzi Lohrasb, Bagherpour Raheb et al (2017) Model uncertainty of various settlement estimation methods in shallow tunnels excavation; case study: Qom subway tunnel[J]. Journal of African earth sciences, 2017, 134(Oct. ): 658-664.

Liu SH, Yuan JY, Zhao X et al (2014) Summary of research on foundation settlement prediction models[J]. Industrial Construction: 738-741, 681. (in Chinese)

Tan J, Cui ZD, Yuan L et al (2016) Study on the Long-term Settlement of Subway Tunnel in Soft Soil Area[J]. Marine Georesources \& Geotechnology, 2016, 34(5): 486-492.

Ahangari Kaveh, Moeinossadat Sayed Rahim, Behnia Danial et al (2015) Estimation of tunnelling-induced settlement by modern intelligent methods[J]. Soils and foundations, 2015, 55(4): 737-748.

Zai JM, Mei GX et al (2000) Research on the prediction method of settlement in the whole process[J]. Rock and Soil Mechanics, 2000, (4): 322-325 (in Chinese)

Zai JM, Mei GX et al (2000) Application of growth curve in foundation settlement prediction [J]. Journal of Nanjing Institute of Civil Engineering and Architecture, 2000(02): 8-13 (in Chinese)

Wu XW, Pan HP et al (2001) Application of Grey Verhulst Model in Embankment Settlement Prediction[J]. Zhejiang Water Conservancy Science and Technology, 2001, (6): 28-30 (in Chinese)

Fan XQ, Hong BN et al (2007) Application of Logistic and Gompertz curves and their optimal combination model in settlement prediction[J]. Journal of Disaster Prevention and Mitigation Engineering, 2007, (2): 192-196 (in Chinese)

Zhang C, Peng ZB, Peng WX et al (2017) Application of optimized gray discrete Verhulst model in foundation pit settlement prediction[J]. Journal of Central South University (Natural Science Edition), 2017, 48(11): 3030-3036 (in Chinese)

Bai GB, Li JZ, Liu S et al (2013) Deformation Monitoring and Data Analysis for Metro Construction with Mining Method in Dalian[J]. Applied Mechanics and Materials, 2013, 2545(709): 1604-1608. 
Song J, Rong XY, Fan YY et al (2012) Measurement Analysis of the Influence of Subway Station Construction to the Adjacent Building and Ground Surface Deformation[J]. Advanced Materials Research, 2012, 1793(1041): 4399-4404.

\section{Figures}

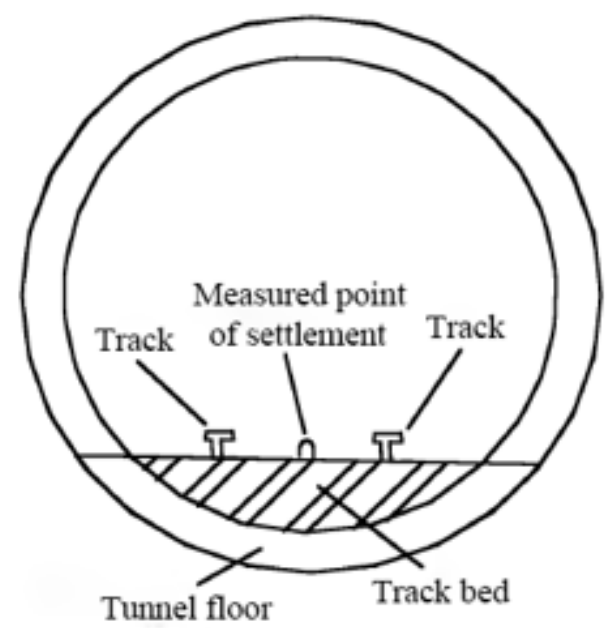

\section{Figure 1}

Schematic diagram of monitoring point layout section

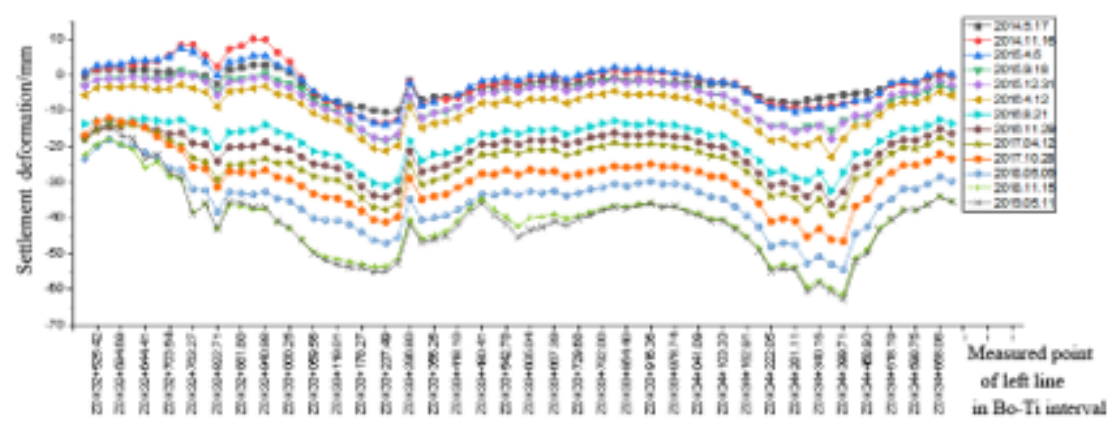

Fig. 2a Cumulative settlement curve of the left line of Bo-Ti interval

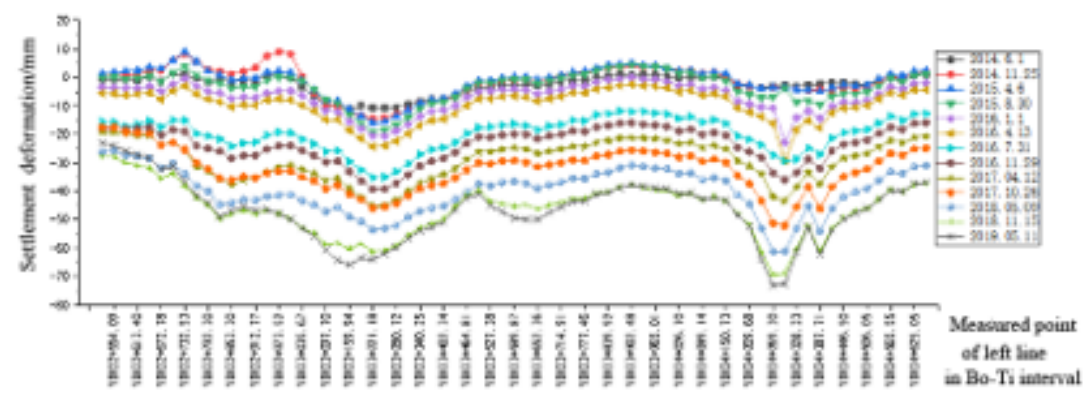

Fig. 2b Cumulative settlement curve of the left line of the Bo-Ti interval

\section{Figure 2}


a Cumulative settlement curve of the left line of Bo-Ti interval b Cumulative settlement curve of the left line of the Bo-Ti interval

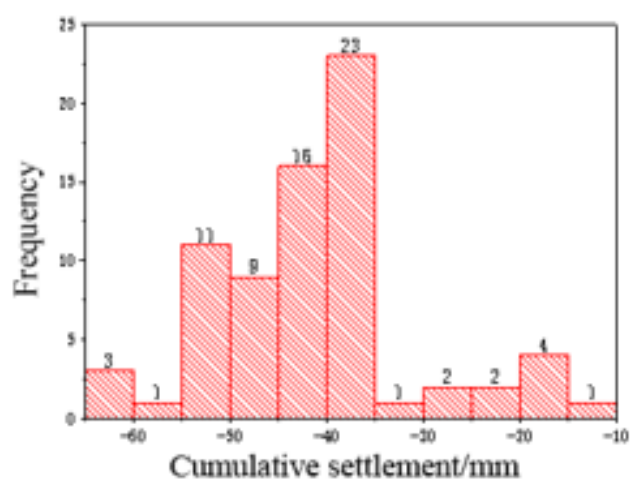

Fig. 3a The frequency distribution of the left line settlement in the Bo-Tibet interval

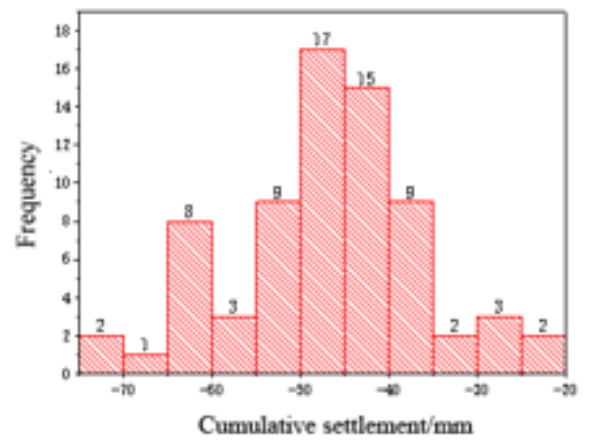

Fig. 3b The frequency distribution of subsidence on the right line of the Bo-Tibet section

\section{Figure 3}

a The frequency distribution of the left line settlement in the Bo-Tibet interval $b$ The frequency distribution of subsidence on the right line of the Bo-Tibet section 


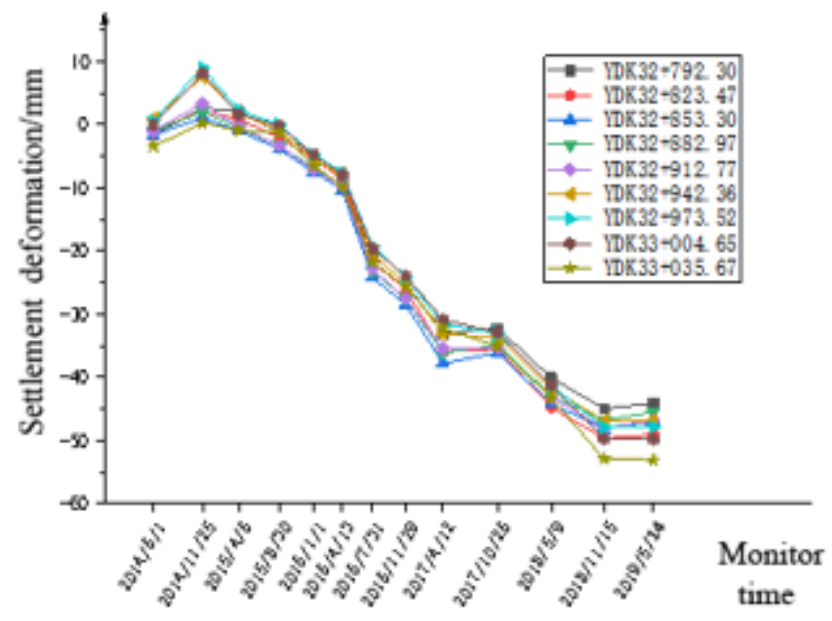

Fig. 4a Settlement-time curve of the right line of the Bo-Tibet section

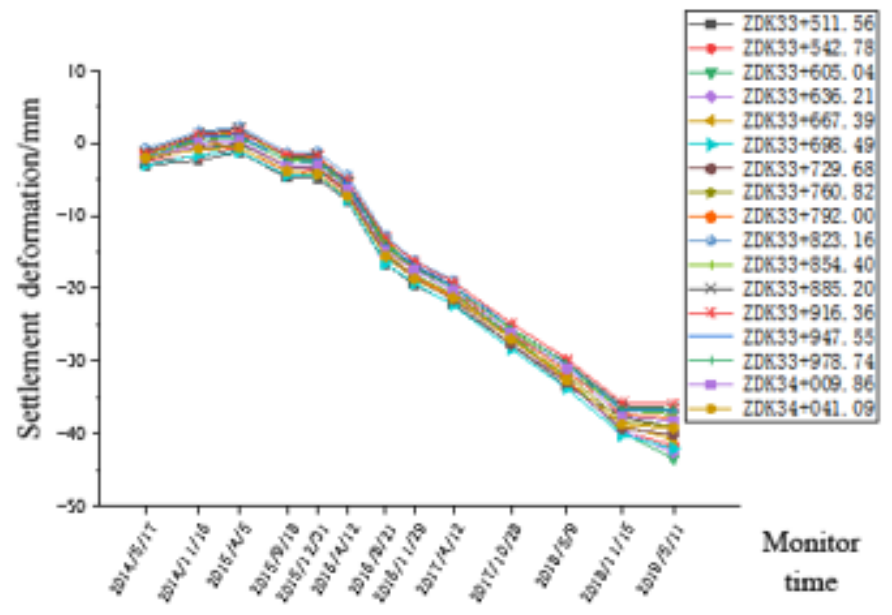

Fig. 4b The settlement development curve of the left line of the Bo-Ti section

\section{Figure 4}

a Settlement-time curve of the right line of the Bo-Tibet section b The settlement development curve of the left line of the Bo-Ti section 


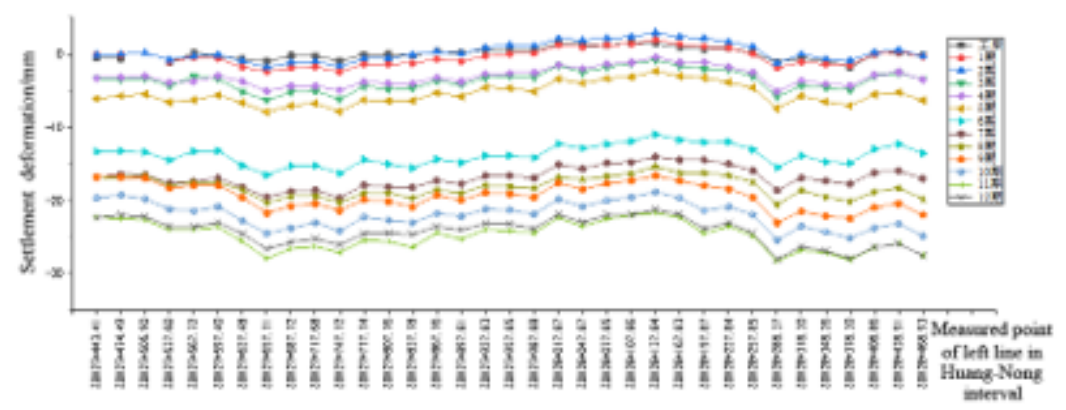

Fig. 5a Cumulative settlement diagram of the left line of the Huang-Nong interval

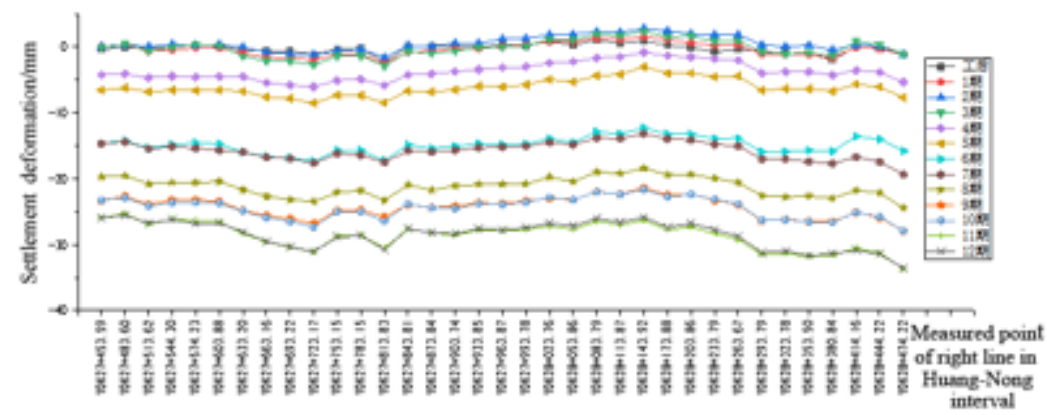

Fig. 5b Cumulative settlement diagram of the right line of the Huang-Nong Interval

Figure 5

a Cumulative settlement diagram of the left line of the Huang-Nong interval $b$ Cumulative settlement diagram of the right line of the Huang-Nong Interval 


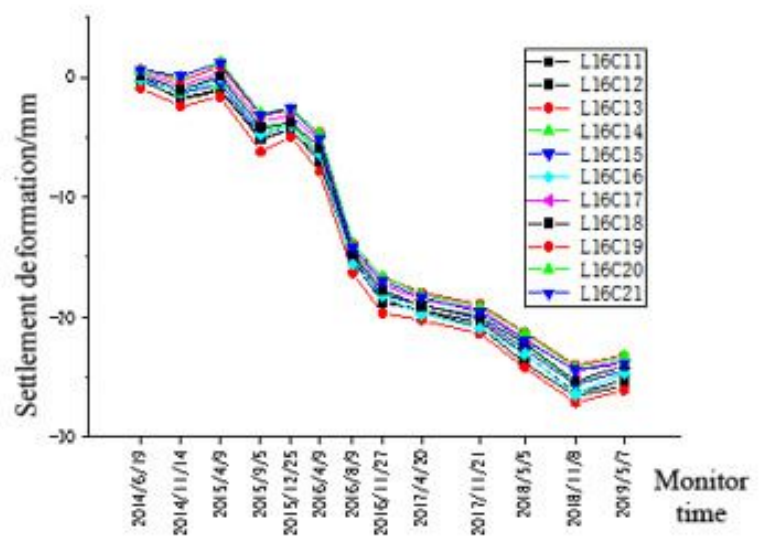

Fig. 6a Settlement-time curve of the left line of the Huang-Nong interval

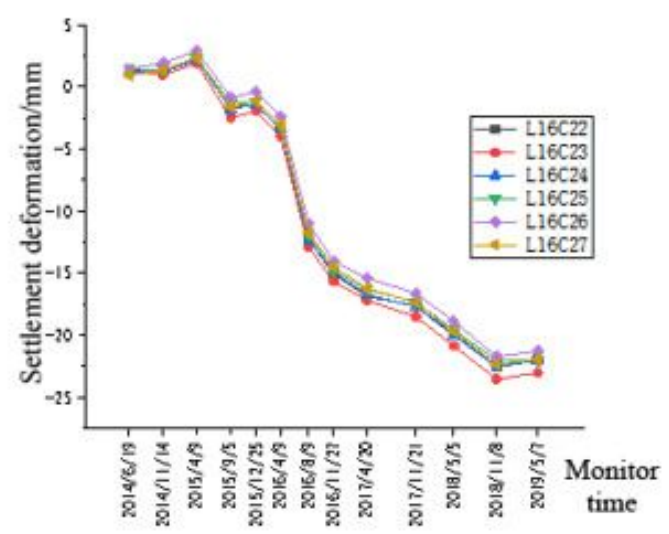

Fig. $6 \mathbf{b}$ Settlement-time curve of the left line of the Huang-Nong interval

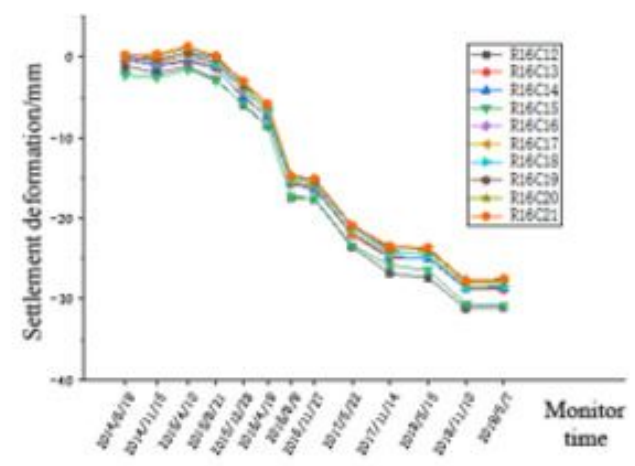

Fig. 6c Settlement-time curve of the right line of the Huang-Nong section

\section{Figure 6}

a Settlement-time curve of the left line of the Huang-Nong interval b Settlement-time curve of the left line of the Huang-Nong interval c Settlement-time curve of the right line of the Huang-Nong section 


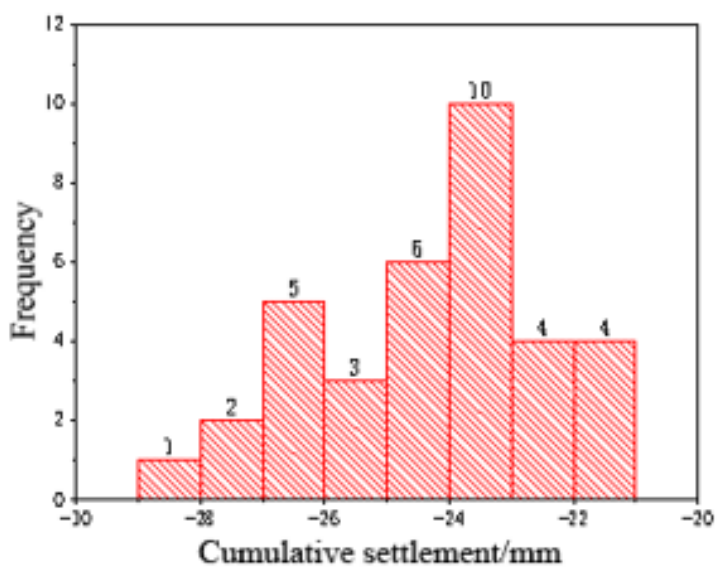

Fig. 7a The frequency distribution of settlement of the left line of the Huang-Nong interval

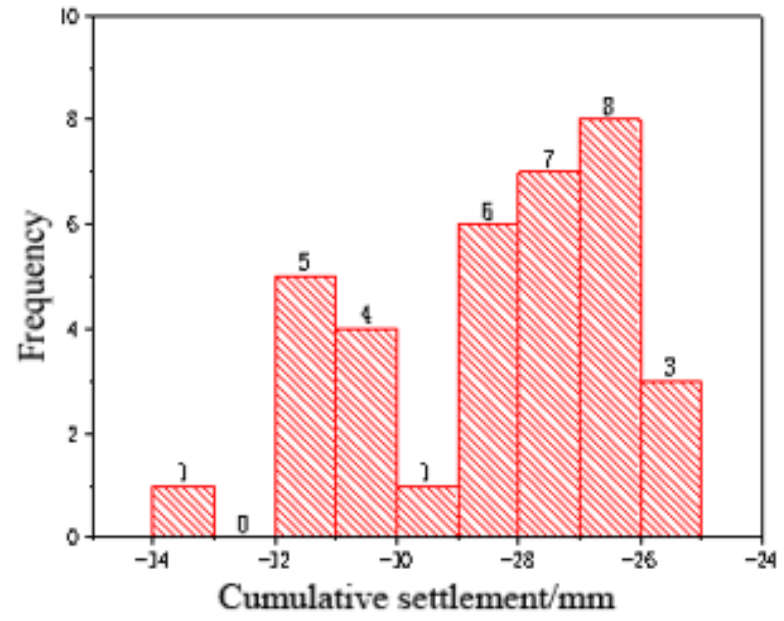

Fig. 7b The frequency distribution of settlement of the right line of the Huang-Nong interval

\section{Figure 7}

a The frequency distribution of settlement of the left line of the Huang-Nong interval b The frequency distribution of settlement of the right line of the Huang-Nong interval 


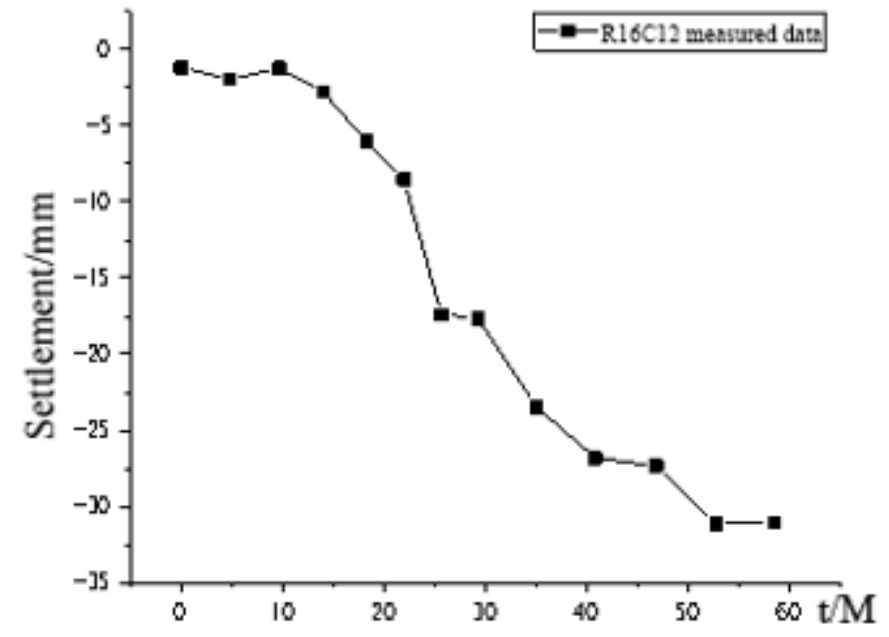

Fig. 8a Settlement-time curve of R16C12 monitoring point

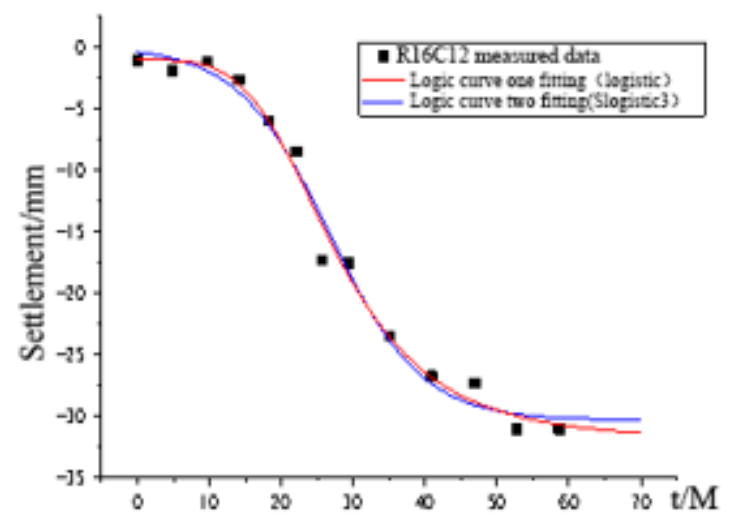

Fig. 8b Logical curve fitting of R16C12 monitoring points

\section{Figure 8}

a Settlement-time curve of R16C12 monitoring point b Logical curve fitting of R16C12 monitoring points 


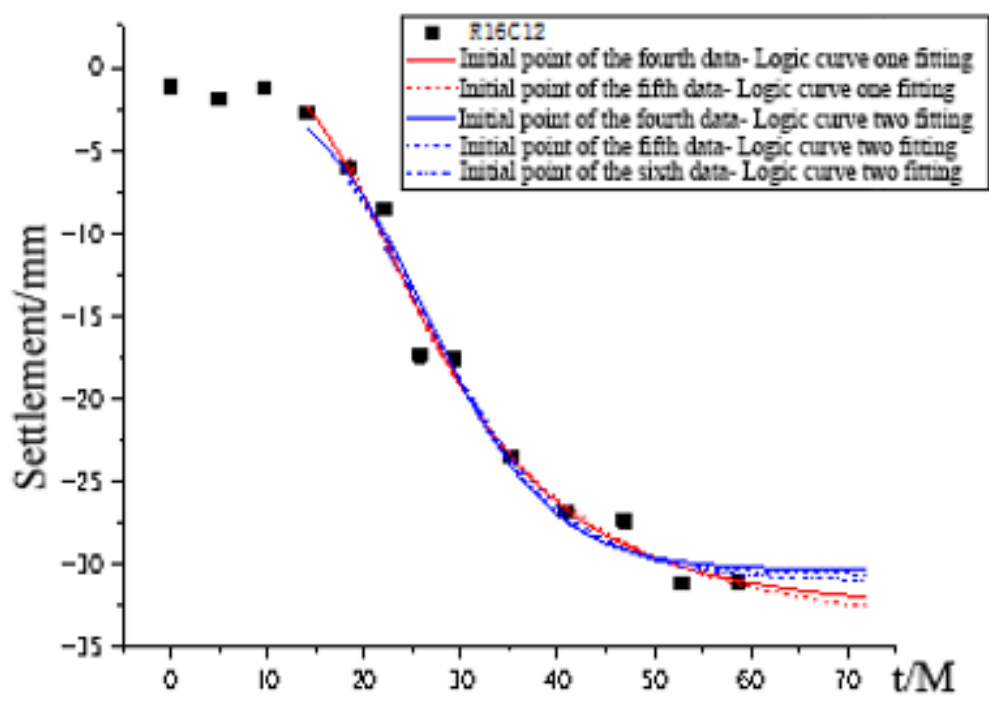

Figure 9

R16C12 logistic curve fitting for different monitoring points 